\title{
Publisher Correction: High-performance virtual screening by targeting a high-resolution RNA dynamic ensemble
}

Laura R. Ganser, Janghyun Lee, Atul Rangadurai, Dawn K. Merriman, Megan L. Kelly, Aman D. Kansal,

Bharathwaj Sathyamoorthy and Hashim M. Al-Hashimi (i)

Correction to: Nature Structural \& Molecular Biology https://doi.org/10.1038/s41594-018-0062-4, published online 4 May 2018.

The HTML version of this Technical Report was incorrectly published under an Open Access license; this has now been corrected.

The PDF was unaffected.

Published online: 6 May 2020

https://doi.org/10.1038/s41594-020-0434-4

(c) The Author(s), under exclusive licence to Springer Nature America, Inc. 2020

\section{Publisher Correction: SLX4 interacts with RTEL1 to prevent transcription-mediated DNA replication perturbations}

\author{
A. Takedachi, E. Despras, S. Scaglione, R. Guérois $\mathbb{D}$, J. H. Guervilly, M. Blin, S. Audebert (1D, L. Camoin, Z. Hasanova, \\ M. Schertzer, A. Guille, D. Churikov (D), I. Callebaut, V. Naim, M. Chaffanet (1D, J. P. Borg D, F. Bertucci, P. Revy, D. Birnbaum, \\ A. Londoño-Vallejo (D, P. L. Kannouche and P. H. L. Gaillard (1)
}

Correction to: Nature Structural \& Molecular Biology https://doi.org/10.1038/s41594-020-0419-3, published online 11 May 2020.

In the version of this article initially published, the affiliation information for each author and the order of affiliations were incorrect. The correct affiliations are: A. Takedachi ${ }^{1,2,10,12}$, E. Despras ${ }^{3,12}$, S. Scaglione ${ }^{1}$, R. Guérois ${ }^{4}$, J. H. Guervilly $^{1}$, M. Blin ${ }^{1}$, S. Audebert ${ }^{1}$, L. Camoin ${ }^{1}$, Z. Hasanova $^{1,11}$, M. Schertzer ${ }^{5,6}$, A. Guille ${ }^{1}$, D. Churikov ${ }^{1}$, I. Callebaut ${ }^{7}$, V. Naim ${ }^{8}$, M. Chaffanet ${ }^{1}$, J. P. Borg ${ }^{1}$, F. Bertucci ${ }^{1}$, P. Revy ${ }^{9}$, D. Birnbaum ${ }^{1}$, A. Londoño-Vallejo ${ }^{5,6}$, P. L. Kannouche ${ }^{3}$ and P. H. L. Gaillard ${ }^{1}$. The correct order of the affiliations is: ${ }^{1}$ Centre de Recherche en Cancérologie de Marseille, CRCM, Inserm, CNRS, Aix-Marseille Université, Institut Paoli-Calmettes, Marseille, France. ${ }^{2}$ Inovarion, Paris, France. ${ }^{3} \mathrm{CNRS}$ UMR9019, Université Paris-Saclay, Equipe labellisée Ligue contre le Cancer, Gustave Roussy, Villejuif, France. ${ }^{4}$ Institute for Integrative Biology of the Cell (I2BC), CEA, CNRS, Univ. Paris-Sud, Université Paris-Saclay, Gif-sur-Yvette cedex, France. ${ }^{5}$ Institut Curie, PSL Research University, CNRS, UMR3244, Paris, France. ${ }^{6}$ Sorbonne Universités, UPMC Univ. Paris 06, CNRS, UMR3244, Paris, France. ${ }^{7}$ Sorbonne Université, Muséum National d'Histoire Naturelle, UMR CNRS 7590, IRD, Institut de Minéralogie, de Physique des Matériaux et de Cosmochimie, IMPMC, Paris, France. ${ }^{8}$ CNRS UMR9019, Université Paris-Saclay, Gustave Roussy, Villejuif, France. ${ }^{9}$ INSERM UMR 1163, Laboratory of Genome Dynamics in the Immune System, Equipe labellisée La Ligue contre le Cancer, Paris Descartes-Sorbonne Paris Cité University, Imagine Institute, Paris, France. ${ }^{10}$ Present address: Department of Chemistry, Faculty of Science, Fukuoka University, Fukuoka, Japan. ${ }^{11}$ Present address: Institute of Molecular Genetics, Prague, Czech Republic. ${ }^{12}$ These authors contributed equally: A. Takedachi, E. Despras. The errors have been corrected in the HTML and PDF versions of the article.

Published online: 14 May 2020

https://doi.org/10.1038/s41594-020-0447-z

$\odot$ The Author(s), under exclusive licence to Springer Nature America, Inc. 2020

\section{Publisher Correction: The oligomeric structures of plant cryptochromes}

Kai Shao, Xue Zhang, Xu Li, Yahui Hao, Xiaowei Huang, Miaolian Ma, Minhua Zhang, Fang Yu, Hongtao Liu and Peng Zhang (D)

Correction to: Nature Structural \& Molecular Biology https://doi.org/10.1038/s41594-020-0420-x, published online 11 May 2020.

In the version of this article initially published, the superscript numbers denoting the amino acid residues in the AtCIB1 ${ }^{16-43}$ peptide construct were incorrectly linked as reference citations throughout the article. The error has been corrected in the HTML and PDF versions of the article.

Published online: 18 May 2020

https://doi.org/10.1038/s41594-020-0449-X

(c) The Author(s), under exclusive licence to Springer Nature America, Inc. 2020 